\title{
CAPITAL SOCIAL: CONTRIBUIÇÕES E PERSPECTIVAS TEÓRICO- METODOLÓGICAS PARA A ANÁLISE DE REDES DE COOPERAÇÃO PRODUTIVA E AGLOMERAÇÕES DE EMPRESAS
}

\section{SOCIAL CAPITAL: CONTRIBUTIONS AND THEORETICAL- METHODOLOGICAL PERSPECTIVES FOR THE ANALYSIS OF PRODUCTIVE COOPERATION NETWORKS AND ENTERPRISES' CLUSTERS}

\author{
João Amato Neto ${ }^{1}$; Rita de Cássia Fucci Amato ${ }^{2}$ \\ ${ }^{1}$ Universidade de São Paulo - USP - São Paulo - Brasil \\ amato@usp.br \\ ${ }^{2}$ Universidade Federal de São Carlos - UFSCar - São Carlos - Brasil \\ fucciamato@terra.com.br
}

\begin{abstract}
Resumo
Nos últimos anos, é notável o crescimento, por parte das micro, pequenas e médias empresas (MPMEs), da busca pela cooperação produtiva em forma de redes, sejam estas espacialmente localizadas, como os clusters regionais, sejam organizações virtuais e redes dispersas espacialmente, como meio de aumentarem sua competitividade. Nesse sentido, cabe destacar o conceito de capital social como fator para a cooperação entre empresas e organizações e como meio para o desenvolvimento de habilidades na busca de maior eficiência coletiva entre os agentes que participam de uma dada rede de cooperação. Assim, o presente artigo objetiva analisar a influência do capital social no desenvolvimento de relações de cooperação produtiva - redes $e$ aglomerações de empresas -, contribuindo para a composição de um referencial teóricometodológico para pesquisas sobre o tema. Baseando-se em uma revisão bibliográfica, o trabalho, de caráter exploratório e multidisciplinar, procurou destacar as principais contribuições teóricas apresentadas por diversas áreas do conhecimento, como a administração, a economia, a engenharia de produção e a sociologia. Também são apresentadas algumas diretrizes para a avaliação do capital social e de suas interfaces com outras formas de capital em redes $e$ aglomerações de empresas. Por fim, o trabalho revela os benefícios proporcionados às empresas pela acumulação de capital social, beneficiando sua competitividade.
\end{abstract}

Palavras-chave: capital social, redes de cooperação produtiva, aglomerações regionais.

\section{Introdução}

A partir do pós-guerra e, em especial, a partir dos anos 1970, uma nova configuração se apresentou para a economia mundial e, em particular, para os sistemas de produção industrial. Essa nova configuração, que trouxe o Japão como uma nova potência industrial, implicou em profundas 
mudanças nas tradicionais formas de organização industrial em geral, e na produção, em particular. Tais mudanças podem ser compreendidas, principalmente, através de três elementos básicos, quais sejam: as novas formas de organização do trabalho; a revolução na base técnica com o advento das novas tecnologias de base microeletrônica; e, finalmente, porém não menos importante, o novo padrão de inter-relacionamento entre firmas (HOFFMAN e KAPLINSKY, 1989).

Dentro deste novo paradigma industrial, surgem tendências do ponto de vista das estratégias e das relações entre empresas, que podem ser estruturadas por meio de alianças estratégicas (KANTER, 1990) ou redes de empresas (PyKE, 1992; PORTER, 1998a; 1998b; GRANDORI e SODA, 1995; CASAROTO FILHO; PIRES, 1999; AMATO NETO, 2000; 2005). Também nesse contexto, as relações interorganizacionais de cooperação produtiva em rede estabeleceram-se, em grande parte, pela concentração espacial de empresas, constituindo os complexos industriais (HAGUENAUER; GUIMARÃES, 1983; GUIMARÃES, 1982; POSSAS, 1984) e os clusters regionais (PORTER, 1998a; 1998b; HUMPHREY; SCHMITZ, 1998) ou arranjos produtivos locais (BNDES, 2003; SEBRAE, 2004; CASSIOLATO; LASTRES, 2003; SUZIGAN, 2001).

As relações de cooperação produtiva, segundo Santos et al (1994), podem ser: verticais, quando empresas, normalmente de pequeno e médio porte, atuam como fornecedoras de indústrias, geralmente de grande porte, por meio da desintegração vertical de processos ou terceirização (caso do complexo automobilístico brasileiro); ou horizontais, quando pequenas e médias empresas (PMEs), na maioria dos casos, fabricam o mesmo tipo de produto e pertencem a um mesmo setor ou ramo de atuação, buscando cooperar para atender uma série de necessidades mútuas que seriam de difícil satisfação nos casos em que as empresas atuam isoladamente, como o fortalecimento do poder de compra e a partilha de riscos e custos de explorar novas oportunidades, realizando experiências em conjunto (AMATO NETO, 2000). Para a realização de tais atividades conjuntas e para o fortalecimento de seu poder competitivo, uma rede de empresas tem que estabelecer objetivos e metas comuns a todos os seus integrantes, obtendo uma coesão entre todas as organizações participantes de tal parceria.

O presente estudo visa analisar a influência do capital social no estabelecimento das relações de cooperação inter-firmas, destacando a importância da coordenação entre os agentes de uma rede de inter-cooperação, sejam estes micro, pequenas e médias empresas (MPMEs), empresas de grande porte, instituições de ensino superior, institutos de pesquisa e desenvolvimento (P\&D), organizações não-governamentais e outras. Quanto à metodologia, a investigação tem um caráter exploratório, baseando-se em uma revisão de literatura multidisciplinar, envolvendo as áreas de engenharia de produção/ engenharia industrial, economia industrial, administração de empresas e sociologia. 


\section{Redes e capital social em relações de cooperação produtiva}

A análise do capital social de uma dada comunidade, bem como de relações inter-firmas, pode ser realizada por meio do artifício analítico de rede. As redes constituem-se em objeto de investigação dos mais diversos campos do conhecimento, como a sociologia, a educação, a ciência da informação/informática, a matemática, a economia, a engenharia e a administração (incluindo a teoria organizacional, a pesquisa operacional, a teoria da comunicação e a teoria dos pequenos grupos), conforme comentam autores como Castells (2000), Brito (2002) e Porter (1998a).

Quanto às redes interorganizacionais, a definição mais aceita é aquela que as considera como um método de organização das atividades econômicas por meio da coordenação e da cooperação entre instituições (PORTER, 1998a). Dessa forma, as redes estão situadas no âmago da teoria organizacional, podendo-se compreender que uma rede inter-firmas constitui-se no modo de se regular a interdependência de sistemas complementares (produção, pesquisa, engenharia, coordenação e outros), o que é diferente de agregá-los em uma única firma. Portanto, as competências e atribuições de uma rede de empresas estão basicamente ligadas aos processos de coordenação que uma coalizão inter-firmas pode empregar. A economia organizacional adicionou à explicação do relativo sucesso das redes a redução dos custos de gerenciamento para os custos de produção, e este tem sido o enfoque mais amplamente utilizado na análise de redes, posto que ajuda a entender a natureza desses meios de regulação econômica como formas híbridas eficientes, que equilibram as propriedades do mercado e das hierarquias (WILLIAMSOM, 1985). Vale lembrar que uma rede de cooperação produtiva é entendida como uma das possíveis maneiras de micro, pequenas e médias empresas (MPMEs) reduzirem os custos, aumentarem a eficiência, a qualidade de seus produtos e os canais de distribuição, além de reduzirem o tempo de resposta ao mercado, através dos ganhos de escala e escopo que são proporcionados pelo equilíbrio entre a cooperação a competição (PYKE; SENGENBERGER, 1992).

Segundo Ribault, Martinet e Lebidois (1995), a sociedade de empresas, também chamada de redes de empresas, consiste em um tipo de agrupamento de empresas cujo objetivo principal é o de fortalecer as atividades de cada um dos participantes da rede, sem que, necessariamente, estas tenham laços financeiros entre si. Atuando em redes, as empresas podem complementar-se umas às outras, tanto nos aspectos técnicos (meios produtivos), como mercadológicos (redes de distribuição). Por outro lado, a constituição de uma rede de empresas pode ter por objetivo, por exemplo, a criação de uma central de compras comum às empresas da rede. Trata-se, pois, de um modo de associação por afinidade de natureza informal e que deixa cada uma das empresas responsável pelo seu próprio desenvolvimento. 
$\mathrm{Na}$ formação das redes inter-firmas, pode-se identificar três variáveis determinantes, quais sejam: a diferenciação, a interdependência entre firmas e a flexibilidade. A diferenciação, quando relacionada a uma rede, pode prover seus benefícios inovativos a todos os seus participantes, o mesmo não ocorrendo para uma firma isolada, dado que a diferenciação pode, nesse caso, gerar elevação nos seus custos. Já a interdependência entre as firmas traduz-se por um mecanismo que efetivamente prediz a formação de redes e, por isso mesmo, é adotado como uma unidade organizacional. Finalmente, a flexibilidade, entendida aqui tanto no aspecto inovador e produtivo como no próprio aspecto organizacional, é uma das maiores propriedades das redes, já que algumas destas podem se auto-arranjar de acordo com suas contingências.

Pelo próprio fato de se traduzirem em idéias e na prática das organizações, os conceitos de redes de empresas ou teias organizacionais se confundem na literatura corrente. Podem, por outro lado, serem considerados, também, como formas especiais de alianças estratégicas entre empresas e outras organizações.

Quanto às redes sociais, relativas ao capital social, estas podem ser entendidas como fluxos de relacionamentos interpessoais que permitem a vinculação entre as pessoas por meio de relações de confiança e cooperação na busca pelo sucesso mútuo dos participantes de tais redes. As redes sociais podem também ser consideradas "redes de funções no interior das associações humanas" (ELIAS, 1997a, p. 22) e "teias de interdependência ou configurações de muitos tipos, tais como famílias, escolas, cidades, estratos sociais ou estados" (ELIAS, 1999, p. 15). Tal "rede só é compreensível em termos da maneira como eles [os indivíduos que dela participam] se ligam, de sua relação recíproca [...]" (ELIAS, 1997a, p. 35). A rede está “em constante movimento, como um tecer e destecer ininterrupto das ligações. É assim que efetivamente cresce o indivíduo, partindo de uma rede de pessoas que existiam ante dele para uma rede que ele ajuda a formar" (ELIAS, 1997a, p. 35). Esta tem "alto grau de maleabilidade e adaptabilidade das funções relacionais humanas, [...] [e] é responsável pelo fato de ser o homem, numa medida especial, um ser social, dependente da companhia de outras pessoas" (ELIAS, 1997a, p. 37), podendo ser compreendida quando observamos "pessoas entre pessoas, envolvidas em jogos com os outros” (ELIAS, 1999, p. 132).

Para Pizarro (2003), redes sociais são um conjunto de indivíduos (nós) e relações interindividuais (fenômenos contingentes aos nós/ indivíduos quando fornecem elementos para uma análise da estrutura social). Assim, as redes sociais e a sociedade como um todo podem ser compreendidas como grupos com formas de organização específicas, com particularidades estruturais que constituem as "estruturas e figurações que os indivíduos formam em conjunto" (ELIAS, 1997b, p. 60).

No relacionamento interpessoal/ social: 
O sucesso da ação de um indivíduo depende antes da posição, na estrutura social, dos indivíduos aos quais ele está ligado do que da sua própria posição. E por quê? Devido a vários processos: a circulação das informações é facilitada; as redes de relações podem influenciar positivamente os tomadores de decisão; as relações aumentam a confiança, a credibilidade; as relações reforçam a identidade e o reconhecimento. (DEGENNE, 2004, p. 304)

A definição de capital social também é bastante ampla, dependendo do enfoque que a análise de tal elemento adota. Esse conceito geralmente é definido como uma rede de relações interpessoais e/ ou intergrupais de cooperação na qual seus integrantes, a partir de recursos provenientes de redes sociais, são regidos por determinadas regras, sistemas, crenças, valores, sentimentos (de reconhecimento, respeito, amizade) e confiança, e estabelecem instituições e relacionamentos cujo objetivo é a promoção do grupo a partir da ação conjunta, interação, reconhecimento mútuo e aprendizagem de seus agentes (SILVA, 2006; MARTELETO; SILVA, 2004; BOURDIEU, 1998; SANABIO, 2006; DEGENNE, 2004; SEBRAE, 2004). Portanto, os indivíduos são a fonte e a composição do capital social, muitas vezes formando grupos e redes sociais de cooperação mútua; os indivíduos pertencentes a um grupo podem cooperar com outros pertencentes a este mesmo grupo, como também podem estabelecer parcerias com pessoas ligadas a outros grupos, estabelecendo relações sociais intergrupais. Estudos sobre o capital social buscam, então, analisar as conseqüências e vantagens da

existência simultânea de muitas pessoas, sua vida comum, seus atos recíprocos, a totalidade de suas relações mútuas [...] [dando] origem a algo que nenhum dos indivíduos, considerado isoladamente, algo de que ele faz parte, querendo ou não, uma estrutura de indivíduos interdependentes, uma sociedade [...]. (ELIAS, 1997a, p. 19)

Segundo Maximiano (2006, p. 27), as “organizações são grupos sociais deliberadamente orientados para a realização de objetivos, que, de forma geral, se traduzem no fornecimento de produtos e serviços". Neste sentido, as pessoas são o principal recurso das organizações, agregadas a outros recursos, quer materiais (instalações, espaço, móveis, equipamentos etc.), quer imateriais (tempo e conhecimentos). Dessa forma, as organizações também são constituídas por redes de relacionamento interpessoal e pelo acúmulo das vantagens trazidas pelas mesmas (capital social). Logo, na análise do capital social de organizações (incluindo aí as redes de empresas), urge-se lembrar que estas devem ser consideradas como grupos sociais e seus funcionários, dirigentes e colaboradores são os indivíduos que os integram. Devemos lembrar que somente existem "o indivíduo na companhia de outros, a sociedade como uma sociedade de indivíduos [...]” (ELIAS, 1997a, p. 18). Ademais, “A estrutura e a configuração do controle comportamental de um indivíduo dependem da estrutura das relações entre os indivíduos" (ELIAS, 1997a, p.56). 
Assim, o capital social de uma organização é constituído, fundamentalmente, pelo acúmulo do capital social dos indivíduos que a integram. Estas organizações, no entanto, distribuem seu capital social (coletivo) entre os indivíduos, levando em conta sua hierarquia interna (BOURDIEU, 1998).

Os estudos sobre capital social destacam normalmente três autores principais, segundo Durston (apud MARTELETO; SILVA, 2004): James Coleman (1990), que enfoca o capital social como um recurso do indivíduo que pertence a uma determinada rede, estudando o a importância deste no desenvolvimento do capital humano; Robert Putnam (1996), que investigou a importância do capital social na construção popular e democrática do governo em algumas regiões italianas, destacando o fato deste permitir que a cooperação entre os indivíduos crie círculos virtuosos que promovam o bom desempenho de instituições e da sociedade em geral; e Pierre Bourdieu (1998; 1983), que investigou tal manifestação de capital a partir da hierarquia social, destacando as relações entre os dominantes - indivíduos com mais capital social - e os dominados - aqueles com menos capital social (MARTELETO; SILVA, 2004). Para Marteleto e Silva (2004), as abordagens de Coleman e Putnam consideram o capital social como um meio baseado em normas e redes de relacionamentos interpessoais para o intercâmbio entre indivíduos. Já para Silva (2006), as visões de Bourdieu e Coleman consideram o capital social como qualquer relação horizontal estabelecida, tacitamente ou explicitamente, entre indivíduos e grupos de indivíduos, objetivando a criação de relações econômicas estáveis.

De acordo com Putnam (1996), a partir do capital social recursos individuais são transformados em um bem coletivo, sendo que este é multiplicado a partir de seu uso, pois, como qualquer forma de capital, é cumulativo. Por isso, sua reprodução ou extinção dá-se a partir de círculos virtuosos e círculos viciosos (PUTNAM, 1996; REIS, 2003). O autor coloca que instituições públicas democráticas funcionam melhor onde há alto nível de engajamento cívico e a população participa através de representações sociais locais (cooperação entre todas as instituições), defendendo a importância da comunidade cívica para o desenvolvimento de instituições eficientes (PUTNAM, 1996).

A exposição bourdieuniana relativa a tal temática considera o capital social como

o conjunto de recursos atuais ou potenciais que estão ligados à posse de uma rede durável de relações mais ou menos institucionalizadas de interconhecimento ou, em outros termos, à vinculação a um grupo, como conjunto de agentes que não somente são dotados de propriedades comuns [...], mas também são unidos por ligações permanentes e úteis. Essas ligações são irredutíveis às relações objetivas de proximidade no espaço físico (geográfico) ou no espaço econômico e social porque são fundadas em trocas inseparavelmente materiais e simbólicas cuja instauração e perpetuação supõem o re-conhecimento dessa proximidade. $\mathrm{O}$ volume do capital social que um agente individual possui depende então da extensão da rede de relações que ele pode efetivamente mobilizar e do volume do capital (econômico, cultural ou simbólico) que é posse exclusiva de cada um daqueles a quem está ligado. (BOURDIEU, 1998, p. 67) 
Para o sociólogo, o capital social, apesar de não se reduzir ao capital econômico e cultural, não é independente destes, uma vez que ambas as formas de capital subsidiam o interreconhecimento dos indivíduos e grupos, essencial para a multiplicação do capital social (BOURDIEU, 1998). Assim, a concentração geográfica de empresas, no caso de clusters, e as redes de cooperação virtuais (organizações virtuais) obtêm, por meio da interação entre as organizações que as compõem, a integração entre os recursos humanos de tais organizações, favorecendo o crescimento das relações sociais no interior de tais grupos e proporcionando, às pessoas e às organizações, "lucros materiais como todas as espécies de 'serviços' assegurados por relações úteis, e lucros simbólicos tais como aqueles que estão associados à participação num grupo raro e prestigioso" (BOURDIEU, 1998, p. 68) - no caso de empresas, associados à sua eficiência e competitividade.

A reprodução do capital social depende fundamentalmente da troca mútua de serviços, como, no caso de relações de cooperação produtiva, de informações e conhecimento tecnológico. Portanto, tal reprodução baseia-se, por um lado, em instituições, que favorecem as trocas através da reunião de indivíduos/ grupos com interesses semelhantes, como feiras de exposição de produtos, seminários e cursos conjuntos, no caso de cooperação produtiva. Por outro lado, o capital social é multiplicado pela sociabilidade em si, ou seja, pelos "favores" e trocas realizados entre as pessoas/ organizações ao longo do tempo (BOURDIEU, 1998).

Nessa dimensão, o capital social depende fundamentalmente de redes de poder (ORTIZ, 1983), já que é um recurso escasso e distribuído desigualmente, que determina a posição do indivíduo na hierarquia social (MARTELETO; SILVA, 2004; NOGUEIRA; CATANI, 1998) quanto maior seu capital social, mais elevada sua posição e maior seu poder. Outros autores, como Putnam (1996), não enfatizam a idéia de desigualdade na distribuição do capital social, porém também consideram que a acumulação deste é um processo de aquisição de poder e até de mudança na correlação de forças de indivíduos e grupos (PASSOS at al, 2005).

As relações de cooperação produtiva entre empresas podem ter como base o capital social, como demonstraram Grandori e Soda (1995). Os autores desenvolveram uma tipologia de redes inter-firmas, baseando-se no tipo de mecanismos de coordenação utilizados, no grau de centralização da rede e no grau de formalização desta rede, identificando três tipos básicos de redes de empresas: redes sociais, redes burocráticas e redes proprietárias. Para estes autores, as redes sociais (social networks), na verdade redes de cooperação produtiva baseadas em capital social, têm por característica fundamental a informalidade nas relações inter-empresariais; isto é, prescindem de qualquer tipo de acordo ou contrato formal. Estão direcionadas para o intercâmbio da chamada 
mercadoria social (prestígio, status, mobilidade profissional e outros). São, ainda, subdivididas em redes sociais simétricas e assimétricas.

As redes sociais simétricas se caracterizam pela inexistência de poder centralizado, ou seja, todos os participantes desta rede compartilham a mesma capacidade de influência. São arranjos interorganizacionais empregados em projetos de caráter mais exploratório, cujas informações são de alto potencial, porém de valor econômico desconhecido. São típicos os exemplos dos pólos e distritos de alta tecnologia, onde há, via-de-regra, uma intensa troca de informações e de conhecimentos entre as partes, sendo sua coordenação realizada através de mecanismos informais (GRANDORI; SODA, 1995). Podemos identificar exemplos de redes sociais simétricas em diversos países, como nos Estados Unidos (o Vale do Silício, na Califórnia, e a Rota 128, em Boston) e no Brasil (o Centro Incubador de Empresas Tecnológicas da Universidade de São Paulo CIETEC/USP -, a Fundação Parque de Alta Tecnologia de São Carlos - Parqtec -, e o Porto Digital, em Pernambuco).

Já nas redes sociais assimétricas há a presença de um agente central, que tem por função primordial coordenar os contratos formais de fornecimento de produtos e/ ou serviços entre as empresas/ organizações que participam desta rede. Um exemplo é rede a italiana de fornecimento da Benetton (GRANDORI; SODA, 1995).

Destaca-se o fato de que os clusters e redes de cooperação produtiva são, geralmente, formados por micro, pequenas e médias empresas (MPMEs), que geralmente tem em sua organização vários aspectos informais, com pessoas ligadas por vínculos afetivos, como o que ocorre em pequenos grupos ou comunidades. Portanto, o trabalho de Elias e Scotson (2000), que estudaram, sob a perspectiva sociológica, as relações de poder a partir de uma pequena comunidade, pode fornecer elementos para o entendimento dessa relação de cooperação.

Em redes de empresas, um maior capital social pode ser considerado como uma fonte de diferenciais de poder entre grupos inter-relacionados, estabelecidos ou outsiders. Um establishment é um grupo que se identifica, auto-representa e é reconhecido como uma "boa sociedade", influente e melhor, construída sobre os pilares da tradição, da autoridade e da influência, presentes decisivamente nessa identidade social. Por outro lado, os outsiders são concebidos como os nãomembros de tal sociedade, aglutinados em um agrupamento heterogêneo e difuso com relações interpessoais de menor intensidade que os establishment (ELIAS e SCOTSON, 2000; NEIBURG, 2000). Grupos estabelecidos caracterizam-se ainda por desfrutarem de estratégias de distinção, como a tradição e a posse de bens raros (BOURDIEU, 1983), e por apresentarem mecanismos de reprodução social, como a escolarização, que lhes permitem certa segurança de permanência em posição superior (BOURDIEU, 1974; NOGUEIRA; CATANI, 1998).

Em clusters e redes de empresas, o principal desafio, portanto, é estabelecer um grau de 
coesão interna que permita que as empresas estejam fortemente integradas e participem de forma ativa e democrática das decisões tomadas em nome do grupo. Assim, a cooperação entre empresas passa a gerar vantagens competitivas frente àquelas empresas isoladas (que, a partir da perda de mercados e eficiência, podem ser consideradas outsiders), uma vez que grupos estabelecidos tem maior poder para competir com outsiders, preservando sua identidade e afirmando sua superioridade (ELIAS; SCOTSON, 2000).

A categorização dos grupos estabelecidos passa por um carisma grupal, que pode ser considerado um paralelo de Elias e Scotson (2000, p. 26) para o conceito de capital social. Todos os que estão inseridos em uma rede de relacionamentos de um grupo estabelecido participam do carisma grupal e se submetem às regras mais ou menos rígidas do grupo, com o sacrifício da satisfação pessoal, em prol do fortalecimento e coesão da coletividade.

[...] os grupos dominantes com uma elevada superioridade de forças atribuem a si mesmos, como coletividades, e também àqueles que os integram, como famílias e os indivíduos, um carisma grupal característico. Todos os que "estão inseridos" neles participam desse carisma. Porém têm que pagar um preço. A participação na superioridade de um grupo e em seu carisma grupal singular é, por assim dizer, a recompensa pela submissão às normas específicas do grupo. Esse preço tem que ser individualmente pago por cada um de seus membros, através da sujeição de sua conduta a padrões específicos de controle de afetos. [...] A satisfação que cada um extraída participação no carisma do grupo compensa o sacrifício da satisfação pessoal decorrente da submissão às normas grupais. (ELIAS e SCOTSON, 2000, p. 26-7)

Vale lembrar, entretanto, que uma figuração estabelecidos-outsiders é mutável, revelando uma "complexa polifonia do movimento de ascensão e declínio dos grupos ao longo do tempo" (ELIAS; SCOTSON, 2000, p. 36), pois “a rede de ligações é o produto das estratégias de investimento social consciente ou inconscientemente orientadas para a instituição ou a reprodução de relações sociais diretamente utilizáveis" (BOURDIEU, 1998, p. 68). No caso de empresas, tal fato pode significar que a busca por vantagem competitiva não deve ignorar a necessidade constante de estabelecer novas parcerias para o fortalecimento da rede de cooperação.

Os arranjos interorganizacionais e a cooperação entre empresas via redes surgiram justamente na busca de maior eficácia na alocação espacial de investimentos produtivos em sintonia com a elevação do poder de competitividade das empresas, relacionando-se com novos padrões tanto de localização de investimentos, que rompem com as tradicionais tendências baseadas em critérios convencionais das vantagens competitivas tradicionais de oferta abundante de matériasprimas e de mão-de-obra baratas, proximidade com mercado consumidor favorável e outros. Sob um contexto marcado pelo advento de um paradigma de produção enxuta, ágil e flexível, a emergência de novos empreendimentos está cada vez mais condicionada pelas atuais tendências de descentralização geográfica da produção. É justamente este aspecto dinâmico de cooperação entre 
um grupo de empresas, que operam na mesma cadeia produtiva - e não simplesmente em nível de cada empresa - na busca das eficiências coletivas que se destaca. Tal constatação deve-se ao fato de que, na economia atual, as decisões de investimentos estão cada vez mais condicionadas por essas vantagens competitivas dinâmicas, como a existência de uma infra-estrutura local adequada; proximidade com centros de pesquisa e desenvolvimento; oferta de mão-de-obra qualificada; acesso aos modernos meios de transporte e de comunicação e outras (AMATO NETO, 2000). Nesse contexto,

[...] o capital social vem se firmando como um dos fatores mais importantes para o desenvolvimento econômico. No que concerne à clusterização, em muitos casos, componentes desse tipo de capital têm sido apontados como fatores cruciais para o sucesso da organização econômica porque criam um ambiente propício para os negócios e incentivam o comércio e as inovações. Por reduzir os custos de transação, a existência de instituições estáveis e regras claras garante os contratos, facilita a gestão de conflitos, limita as práticas monopolistas e assegura que as infrações são genalizadas e, portanto, desencorajadas. Em particular, essa redução de custos de transação acelera a transmissão da informação no que diz respeito à difusão e imitação das boas práticas (best practices), aumentando, assim, a sinergia entre o grupo de empresas que compõem o cluster. A essas regras formais juntam-se ainda elementos informais, como confiança mútua e reputação, que fortalecem a interação - fundamental nesses arranjos produtivos - entre as redes de empresas. (SEBRAE, 2004, p. 237)

Portanto, em redes e aglomerações de empresas, o capital social contribui para uma maior interação e coesão entre os interesses pessoais e coletivos e as instituições, promovendo relações de maior confiança entre os membros de uma rede interorganizacional (LIMA, citado por SANABIO, 2006), além de promover, ao lado do capital intelectual e da qualificação profissional, a capacidade de empreendedorismo e, a partir daí, o desenvolvimento local (ALBAGLI; MACIEL, 2002). O capital social também pode ser considerado uma das vantagens competitivas das estruturas localizadas e da associação de empresas, uma vez que estimula a adoção de estratégias coletivas e inibindo comportamentos oportunistas dos agentes envolvidos (GRANOVETTER, 1985). Putnam (apud WEGNER; WITTMANN, 2004; WEGNER et al., 2004) destacou a relevância do capital social na Terceira Itália: nessa região, onde as redes de empresas sob o paradigma de especialização flexível se tornaram um caso de destaque mundial, o autor mostrou que a comunidade cívica foi muito relevante na constituição de redes no âmbito da economia local.

Segundo Marteleto e Silva (2004), há três tipos de capital social: relações sociais entre membros de uma comunidade (capital social de ligação), relações entre membros da comunidade e representantes de organizações não-governamentais (capital social de ponte) e relações entre as lideranças sociais e comunitárias e os representantes das instituições acadêmicas (capital social de conexão). Para os autores,

as redes existentes [...] podem ser vistas de duas óticas complementares: a dos indivíduos envolvidos com as empresas (empresários, gerentes e empregados em geral), na qual os 
laços de amizade e conhecimento são relevantes para os contatos profissionais, e das empresas e organizações (fornecedores de todos os tipos, concorrentes, universidades e associações etc.), na qual os laços econômicos são os objetos da investigação (MARTELETO; SILVA, 2004, p. 47).

\section{Capital social e confiança}

Deve-se destacar a importância da confiança na criação do capital social em redes de cooperação produtiva e clusters regionais: a confiança e a cultura de colaboração fazem com que os as empresas e seus parceiros respeitem os compromissos assumidos entre as organizações participantes da rede, possibilitando respeito mútuo, menores riscos de oportunismo e, sobretudo, o aprendizado do grupo (AMATO NETO, 2000). Assim, a estruturação do capital social tem uma de suas bases na "confiança não apenas individual, mas coletiva. Coletivos inteligentes só podem ser construídos com base na confiança mútua disseminada entre os indivíduos”, na visão de Lopes e Cabelleira (2004, p. 3794). Segundo essas autoras: “A confiança, aspecto fundamental em arranjos produtivos, é produzida entre os atores sociais quando eles compartilham crenças e a constroem baseados em expectativa mútua" (LOPES; CABELLEIRA, 2004, p. 3800).

A inter-cooperação empresarial baseia-se em relações sociais, culturais, econômicas, profissionais e educacionais, como vínculos de parentesco, religião, etnia, escola, e em condições históricas, políticas ou sindicais relacionadas à comunidade local. As relações de confiança permitem o desenvolvimento de alianças entre empresas a partir de interação social, que pressupõe a criação de vínculos sociais duradouros. Assim, as competências relacionais podem gerar oportunidades de inter-cooperação de firmas, a partir da rede pessoal (capital social) do empreendedor. A rede de relações sociais de um empresário pode ainda, a partir de relações de confiança, promover oportunidades de desenvolvimento de seu empreendimento e proporcionar vantagens competitivas. Nesse contexto, as relações de cooperação produtiva requerem confiança, sinergia, sentimento de pertencimento grupal, equilíbrio de poderes, troca de informações transparentes e compartilhamento de valores entre seus agentes (PAIVA JÚNIOR et al, 2006).

Para Becattini (1989) um sistema de valores homogêneos entre empresas de uma rede ou cluster é importante para o afloramento de uma ética presente em diversos aspectos da vida dos distritos. Segundo o autor, a transmissão desses valores através de gerações favoreceria o desenvolvimento de um sistema de instituições e regras a serem seguidas pelos indivíduos da comunidade. O elo proporcionado pelas instituições, seja através do parentesco, etnia, filiação política, religiosa, seja por meio de acordos coletivos, formais ou informais, proporcionam o estabelecimento de um ambiente de confiança pelas empresas. Esse ambiente constrói-se no decorrer do tempo através da experiência e do aprendizado de que trocas sociais podem resultar em 
vastos ganhos (BECATTINI, 1989). O resultado é o senso de crescimento coletivo das empresas, em que cada unidade se beneficia do sucesso do todo (PYKE; SENGENBERGER, 1992).

Para Marteleto e Silva (2004), a confiança é adquirida, dentro de um período de tempo, a partir constantes contratações e recontratações e acordos informais, dentre outros aspectos, criando um ambiente sociocultural, institucional e econômico, com externalidades econômicas, economias de escala, eficiência coletiva, economias de aglomeração, capacidade inovadora, criatividade industrial descentralizada, potencial para o desenvolvimento endógeno no nível regional e local, como também especialização flexível.

A confiança é de fundamental importância no mundo dos negócios, já que todas as transações econômicas envolvem risco, não só relacionado com possíveis fraudes, como também com a imprevisibilidade dos acontecimentos futuros. Tais riscos, se não controlados, podem evitar que negócios que trariam benefícios para todas as partes se concretizem.

Segundo Humphrey e Schmitz (1998), existem duas formas de se lidar com o risco. Uma é por meio de sanções, que criam incentivos, mas também penalizam as empresas que não agirem corretamente. Isto está ligado à idéia de oportunismo defendida por Williamson (1985). Para este autor, toda empresa tem seu preço, todas têm seu nível de oportunismo. Assim, destaca-se a necessidade de um acordo mais formal. O argumento central deste autor refere-se aos chamados custos de transação: transações envolvem incertezas sobre seu sucesso e requerem altos investimentos, por isso tendem a ser internalizadas pela empresa (hierarquia), enquanto transações menos complexas tendem a ocorrer por meio do mercado, já que não requerem investimentos em ativos específico (WILLIAMSON, 1985).

Nessa perspectiva, portanto, mercado e hierarquia referem-se às formas alternativas de coordenação da atividade econômica. Há formas de coordenação, no entanto, que não podem ser asseguradas nem pela firma (hierarquia) nem pelo mercado: decorrem justamente da cooperação entre empresas; são as redes de cooperação inter-firmas, outra forma se dá por meio da confiança. Existem empresas em que podemos confiar, pois nem todas são oportunistas. Neste caso, os riscos são controlados por existir confiança.

A confiança como elemento central nas relações de cooperação e fator decisivo, que faz com que os parceiros respeitem os compromissos assumidos entre as empresas pertencentes a uma dada rede, também é destacada por outros autores. Para Joly e Mangematin (1995), diferentes aspectos se apresentam neste nível: a importância das redes de relações sociais pré-existentes; a importância do respeito mútuo; o aprendizado da relação; a importância da reputação da cada parceiro; os riscos incorridos no caso de comportamento oportunístico, principalmente em termos de exclusão da rede; e o aprendizado de savoir faire social, entre outros. 
Dessa forma, uma das principais características que vem marcando esta transição do paradigma de produção em massa (taylorista-fordista) para o paradigma de produção flexível traduz-se pelo fato de que é possível se pensar, do ponto de vista das estratégias empresariais, em um certo equilíbrio entre cooperação e competição.

\section{Capital social e instituições de apoio a clusters e redes de cooperação produtiva}

O capital social, a cultura de confiança e as entidades de apoio a aglomerações e redes interfirmas foram também destacados por Marshall (1952), que chamou a atenção para as instituições políticas e sociais, assim como para o caráter das pessoas. Segundo o autor, tais fatores seriam determinantes para a prosperidade das indústrias.

Portanto, a presença de instituições de apoio às empresas pertencentes a tais aglomerações e relacionamentos interorganizacionais (chamada infra-estrutura externa às empresas) é um outro aspecto de destaque na análise do capital social em redes de cooperação produtiva e clusters regionais, enfatizada pelo SEBRAE (2004) e também destacada pelo World Bank (2003) como elemento vital para a construção do capital social, já que: "As instituições representam o comportamento cooperativo e são formadas por indivíduos que se unem na busca de um determinado fim, sendo que o resultado efetivo da interação social não depende apenas das instituições, mas também das ações dos seus interlocutores” (GONÇALVES; ABREU, 2004, p. 3778).

Como enfatizado por Bortolotti (2005), a participação da comunidade está intensa e diretamente ligada ao conceito de capital social e passa a constituir, com a ação dos agentes políticos, uma fonte de vantagens ativas para clusters e redes de empresas (MEYER-STAMER, 2001), sendo que estes podem atuar nos por meio de instituições de suporte, participando da atividade meso-econômica como responsáveis pelo desenvolvimento de fatores determinantes de competitividade sistêmica e pela concretização de potenciais tanto locais quanto regionais (MEYER-STAMER, 2001; BORTOLOTTI, 2005). De fato, as instituições são a base para o estabelecimento de redes sociais de relacionamento interpessoal, fornecendo também apoio para a cooperação produtiva interorganizacional.

Dentre as instituições presentes em redes de inter-cooperação e aglomerações de empresas e suas respectivas funções, podemos destacar algumas: governo (municipal, estadual ou federal), fornecedores de matérias-primas, insumos e serviços especializados (como design, marketing e gestão), incubadoras de empresas e parques tecnológicos, entidades de classe, organizações nãogovernamentais (ONGs), instituições de crédito e fomento, escolas de educação básica e ensino técnico-profissionalizante, instituições de ensino superior e institutos/ laboratórios de pesquisa e 
desenvolvimento (P\&D). Estas podem, além de desenvolverem dentro de seu âmbito de atuação ações específicas para as aglomerações e redes inter-empresariais, promover eventos (como feiras, cursos de atualização e workshops), proporcionando oportunidades de desenvolvimento das empresas a partir da (re)qualificação profissional, do contato com novos produtos, processos e tecnologias, da abertura de novos mercados e da concretização de novas parcerias.

Assim, a concentração geográfica e setorial de empresas é um sinal evidente da formação de um conglomerado (cluster), porém não é suficiente para gerar benefícios diretos para todos os seus membros, os quais só podem ser obtidos via um conjunto de fatores facilitadores da eficiência coletiva (SCHMITZ, 1997; 1992; 1991; 1989), dentre os quais se destacam as instituições como os fornecedores de matéria-prima e de máquinas, as empresas especialistas em serviços tecnológicos, financeiros e contábeis e associações para a realização de lobby e de tarefas específicas para o conjunto de seus membros (HUMPHREY; SCHMITZ, 1998).

As experiências internacionais apontam no sentido de que há um papel importante a ser desempenhado pelas pequenas e médias empresas a partir das condições colocadas pelo novo paradigma de produção industrial flexível, surgindo muitas vezes a partir da lógica de maior descentralização produtiva por parte das grandes organizações, com a conseqüente terceirização e subcontratação de serviços das MPMEs. Portanto, esta nova base produtiva deverá estar apoiada em um conjunto de políticas concretas, focalizadas para atender as necessidades de modernização técnica/ gerencial da MPMEs, visando maior poder de competitividade. Cabe ao poder público (diversas esferas do governo: municipal, estadual ou federal), portanto, desenvolver mecanismos coerentes de apoio técnico e, principalmente, gerencial, a fim de viabilizar a existência destas empresas, além de coordenar os esforços de desenvolvimento de novos produtos/ processos, qualificação de pessoal etc. Vale lembrar que nem todas as empresas de porte pequeno ou médio estão em um estágio de desenvolvimento que apresenta condições desta se modernizar o suficiente para competir, ou simplesmente, sobreviver nesse contexto competitivo. Em função disso é que as políticas públicas devem ser seletivas e direcionadas estrategicamente (AMATO NETO, 2000).

O apoio governamental pode também ser traduzido por meio de políticas de financiamento, subsídios, isenção de tributos, promoção e atração de empresas, fortalecimento das redes de relação entre os agentes, contribuição nos esforços de exportação e preservação da indústria frente à concorrência externa (BORTOLOTTI, 2005). Vale ressaltar que o governo também pode atuar por meio de parcerias público-privadas e de agências de desenvolvimento, consórcios e redes entre municípios, como é o caso da Agência de Desenvolvimento do Grande ABC (estado de São Paulo) e da rede de Mercocidades. Casos de apoio estatal recebido para o desenvolvimento de clusters são os pólos tecnológicos do Vale do Silício na Califórnia / EUA e de Campinas, nos quais o Estado 
teve papel fundamental na conformação de diversas das capacitações locais que deram suporte ao processo de desenvolvimento dos sistemas produtivos (GARCIA; AMATO NETO, 2006).

Já no caso de fornecedores de matérias-primas, insumos e serviços especializados (como design, marketing e gestão), as principais vantagens vislumbradas, além da maior qualidade de tais produtos e serviços, são similares àquelas obtidas pelas grandes empresas quando subcontratam MPMEs especializadas, como a eliminação ou minimização de estoques, dentro da lógica do sistema de produção just-in-time, e a redução dos riscos, ao se repassar tarefas específicas de produção e processos para outras empresas (AMATO NETO, 2000).

O papel das incubadoras de empresas e parques tecnológicos muitas vezes é decisivo na criação e desenvolvimento de aglomerações de empresas, como nos casos do Vale do Silício (Califórnia, EUA), da Rota 128 de Massachusetts (Boston, EUA), do conjunto de pequenas firmas de tecnologia de ponta nos arredores de Lyon (França), do Desfiladeiro do Silício (Escócia) e dos centros de tecnologia de ponta ao redor de Cambridge, na rodovia M4, que sai de Londres (Inglaterra), dentre outros (AMATO NETO, 2000).

Uma incubadora de empresas fornece, no contexto de desenvolvimento econômico, apoio adicional durante o primeiro período crítico de vida de empresas, principalmente de pequeno porte, apoiando a transformação de empresários potenciais em empresas crescentes e lucrativas. As incubadoras são arranjos interorganizacionais que visam oferecer infra-estrutura (física, administrativa e operacional), recursos humanos e serviços especializados adequados ao desenvolvimento de empreendimentos nascentes, estimulando e facilitando a integração universidade-empresa, empresa-empresa e setor produtivo-instituições de apoio. Assim, procuram atingir seus objetivos fornecendo apoio técnico e gerencial às empresas incubadas, promovendo e acelerando a consolidação de empresas, estimulando o espírito empreendedor, desenvolvendo ações associativas e compartilhadas, reduzindo custos para o conjunto das empresas e seus parceiros, buscando novos apoios e parcerias para as empresas, divulgando as empresas e seus produtos e participando de outras redes de inter-cooperação. Da mesma forma que em um condomínio residencial, os custos fixos, comuns ao conjunto dos participantes da incubadora são rateados entre as empresas inquilinas (GUEDES; FORMICA, 1997; AMATO NETO, 2000).

Já os parques tecnológicos se afirmaram como uma importante alternativa na indústria mundial, oferecendo uma destacada contribuição para o desenvolvimento de diversos países e regiões. Tais instituições destinam-se, basicamente, a promover uma maior aceleração para a integração entre a pesquisa e o desenvolvimento de novos produtos e processos e sua aplicação nas empresas. Nascem, portanto, em regiões com uma grande densidade de institutos de P\&D e universidades, aplicando, geralmente, tecnologia de ponta em nos processos produtivos, se destinando à produção de itens de alta tecnologia, como instrumentos científicos e médicos, 
principalmente destinados às indústrias farmacêutica e química e ao desenvolvimento de softwares, banco de dados, tecnologia de circuitos integrados, tecnologia de materiais e de produção, biotecnologia, instrumentos ópticos e microbiologia. Pode-se dizer que os parques tecnológicos geraram milhares de conexões que transformaram economias isoladas em uma rede interligada e, certamente, a formação de tais redes é um fator-chave para o sucesso no ambiente competitivo dos dias de hoje (AMATO NETO, 2000). Dentre os principais casos de parques tecnológicos, podem-se citar exemplos nos Estados Unidos (parque tecnológico de Stanford e Vale do Silício), na Holanda (parque tecnológico de Zernike), no Japão (parque da Akademia Kasusa) e no Brasil (Fundação Parque de Alta Tecnologia de São Carlos - Parqtec -, no estado de São Paulo).

Cabe destacar ainda o papel das entidades de classe (com sede ou não nas aglomerações, desde que participem da rede de cooperação interorganizacional), que são as associações, os conselhos, as confederações e os sindicatos, cujo papel principal é o de prover sustentabilidade às profissões regulamentadas através da fiscalização do exercício profissional, da representação política nos assuntos de interesse profissional, de assistência técnica, cultural e social aos associados, do estímulo à formação continuada e assessoria em questões trabalhistas e administrativas.

Como as entidades de classe, as organizações não-governamentais (ONGs), desta vez mais voltadas a um único cluster ou rede de empresas, podem atuar em diversos ramos apoiando o desenvolvimento das empresas, por meio tanto de ações voltadas para o desenvolvimento da comunidade em que se instala o cluster em geral (serviços básicos de educação, saneamento, habitação e saúde), quanto de atividades voltadas à própria gestão da aglomeração ou rede (gestão ambiental, gestão da qualidade e produtividade, etc.).

Releva-se também no desenvolvimento de MPMEs em aglomerações e redes o papel das instituições de crédito e fomento, que são essenciais para que as empresas possam realizar investimentos a curto, médio e longo prazo que visem aumentar sua capacidade competitiva e eficiência. Dentre essas, destacam-se os bancos, que podem atuar por meio de linhas de financiamento para MPMEs, e sociedades garantidoras de crédito - sistemas nacionais, fundos garantidores locais etc. (CASAROTTO FILHO, 2006; CASSAROTTO FILHO; PIRES, 1999; AMATO NETO, 2000).

Com relação a capital social, instituições e capital intelectual, destacam-se as entidades educativas atuantes em aglomerações e redes de empresas, que podem fornecer diversas vantagens competitivas às organizações por meio da qualificação da mão-de-obra. Enquanto as escolas de educação básica e ensino técnico-profissionalizante provém uma formação fundamental aos trabalhadores das indústrias, as universidades capacitam-nos para os processos produtivos e a gestão da produção, sendo também relevantes parceiras no desenvolvimento de pesquisas para a 
melhoria das atividades das empresas da rede, podendo realizar projetos com o apoio de órgão públicos de fomento à ciência, tecnologia e inovação $(C, T \& I)$, incluindo a capacitação (graduação e pós-graduação) de gestores de tais relacionamentos inter-empresariais. Nesse caso, a universidade pode atuar por meio de atividades ensino, pesquisa e extensão, (re)qualificando os trabalhadores, auxiliando as empresas no seu desenvolvimento técnico e organizacional e promovendo cursos e eventos com ambas as finalidades.

Os institutos e laboratórios de pesquisa e desenvolvimento (P\&D) têm um papel de grande importância para o crescimento da competitividade de um cluster ou rede de cooperação produtiva, na medida em que podem representar a criação de produtos de maior qualidade e grau de complexidade tecnológica, com maior valor agregado.

\section{Avaliação do capital social em relacionamentos de inter-cooperação organizacional: algumas propostas}

A dificuldade de mensuração do capital social tem sido destacada por muitos autores e instituições, como Silva (2006), Degenne (2004) e SEBRAE (2004).

Degenne (2004, p. 304) coloca que o capital social pode ser medido levando-se em conta: “(i) quão extensa é a rede em que a pessoa se insere, tendo em vista o sistema de estratificação social, (ii) qual o nível mais levado nele alcançado e (iii) como se distribuem as relações nesse intervalo". Tal abordagem baseia-se nos postulados de Granovetter (apud DEGENNE, 2004, p. 304):

1. Quanto melhor a posição de um indivíduo na estrutura social, maiores serão suas chances de ter acesso e de poder utilizar-se do capital social eficaz.

2. Quanto mais forte o elo à rede, mais oportunidades há de que o capital social correspondente afete positivamente o sucesso da ação considerada.

3. Quanto mais fraco o elo, melhor é o capital social ao qual ele dá acesso.

4. Quanto mais os indivíduos estiverem próximos de pontes - entendidas como o elo que liga diferentes meios sociais -, em uma rede, melhor será seu capital social.

5. O poder de uma posição (em termos de sua proximidade a uma ponte) depende do diferencial de nível, dentro da estrutura social, entre as extremidades dessa ponte.

6. Os efeitos do capital social são limitados às extremidades da hierarquia social (o topo e a base).

Em pesquisas de campo sobre o capital social nas relações interorganizacionais, o SEBRAE (2004), com base em Boisier, sugere que sejam investigados:

- As instituições ou organizações públicas e privadas existentes na região: número, clima de relações interinstitucionais (cooperação, conflito, neutralidade), grau de modernidade.

- $\mathrm{O}$ estoque de conhecimentos e habilidades que os indivíduos que residem na região possuem e sua capacidade para exercitá-los. 
- A tradução de práticas de políticas democráticas, de confiança nas instituições, de preocupação pessoal com os assuntos públicos, de associatividade entre as esferas públicas e privadas.

- O que permite aos membros de uma comunidade confiarem uns nos outros e cooperarem na formação de novos grupos ou em realizar ações em comum.

- A capacidade real ou latente de toda a comunidade para articular, de maneira democrática, as diversas formas de capital intangível disponíveis (institucional, humano, cívico, social, sinergético, cultural, cognitivo e simbólico).

O capital social de uma comunidade onde se instala um cluster pode ser avaliado pelo seu caráter inovador, empreendedor, participativo e associativo, entre outros, abrangendo o impacto da implementação do arranjo produtivo/cluster para a comunidade em termos de empregos e a aceitação da comunidade, com a introdução de cursos específicos em escolas e faculdades da região. Também deve ser abordada a participação ativa de diversas esferas de governo na aglomeração ou rede de cooperação, por meio do desenvolvimento de ações públicas efetivas para o crescimento da indústria, através de políticas de financiamento, subsídios, isenção de tributos, promoção e atração de empresas, fortalecimento das redes de relação entre os agentes, contribuição nos esforços de exportação e preservação da indústria frente à concorrência externa.

Bortolotti (2005) propõe alguns indicadores para a avaliação do capital social em uma relação de cooperação produtiva. Em sua dimensão institucional, este pode ser avaliado por meio da identificação de quais são os agentes que exercem as principais ações públicas efetivas para o desenvolvimento do arranjo produtivo: os governos municipal, estadual ou federal, isoladamente ou em conjunto. Outro indicador das formas de capital social e intelectual é o caráter empreendedor da comunidade, que pode ser vislumbrado pela detecção do número médio de empresas abertas por ano, ligadas ao cluster. Este último indicador, portanto, somente pode ser aplicado a aglomerações, excluindo-se as redes não constituídas espacialmente.

Em interface com o capital intelectual, o capital social pode também ser mensurado pela presença de instituições de aprimoramento técnico na rede de cooperação; ou seja, deve ser investigado se há instituições com cursos profissionalizantes voltados às atividades desenvolvidas pelas empresas. Esse indicador, além de avaliar as atividades voltadas ao abastecimento de profissionais mais qualificados nas empresas, demonstra um envolvimento da comunidade em apoiá-las, uma vez que se estuda para trabalhar diretamente nas empresas da rede ou cluster. Assim, quanto maior a presença de tais cursos profissionalizantes na região do cluster, maior o seu grau de desenvolvimento e maiores as chances de ele se sustentar em termos de oferta de mão-de-obra qualificada (BORTOLOTTI, 2005). 
Em interface com capital humano, o capital social pode ser mensurado não apenas a partir da presença de instituições de ensino na região, mas da interação que estas possuem com as empresas. Essas parcerias podem ocorrer no campo de $\mathrm{P} \& \mathrm{D}$, por parte de universidades, escolas e centros de pesquisa, como podem ocorrer com parcerias de geração do primeiro emprego por parte das empresas. Assim, deve-se analisar qual a porcentagem das empresas que possuem parceria com instituições de ensino, pesquisa e desenvolvimento - destacando, se possível, a evolução de tais parcerias (BORTOLOTTI, 2005).

Por fim, pode-se analisar o capital social pelo que o cluster representa para a comunidade em termos de empregos; caso a aglomeração não crie empregos para os habitantes da região, estes não se sentirão obrigados a se envolver e não se esforçarão em apoiar a indústria em questões cruciais como meio ambiente, imagem das empresas, pressões frente o poder público e ações de promoção. Além disso, um cluster só representa força regional se for responsável por uma boa

parcela da distribuição de renda para a população em termos de oferta de empregos. O indicador escolhido para avaliar esta relação é o índice de população ocupada (\%PO), que revela a porcentagem de empregos gerados pela aglomeração em relação ao total da região. Esse índice pode ser calculado com o uso de dados secundários, dividindo-se o número de empregos oferecidos pela indústria do cluster pelo número de empregos de toda a região (BORTOLOTTI, 2005). Em organizações virtuais (OVs), acredita-se que tal indicador possa ser dispensado, uma vez que tende a ser insignificante, pois OVs, como redes globais de empresas, podem gerar empregos em um número muito grande de regiões.

\section{Considerações finais}

Clusters e redes de cooperação produtiva proporcionam às empresas que os integram vantagens competitivas que não seriam adquiridas caso tais organizações não atuassem em conjunto. Instituições como o SEBRAE (2004) e o Deutsche Gesellschaft für Technische Zusammenarbeit (GTZ, 2006) consideram o capital social como uma das principais bases para a constituição de redes entre organizações, permitindo que estas alcancem maior capacitação, eficiência e melhor desempenho.

Nesse contexto, o capital social se manifesta como uma das principais ferramentas de desenvolvimento de relações de cooperação produtiva. Por meio do relacionamento interpessoal de funcionários, dirigentes e colaboradores de instituição, são detectadas afinidades entre estas no nível da produção e por meio desses contatos podem se estruturar acordos e projetos cooperativos. A afinidade entre os indivíduos pode promover, assim, relações de cooperação interorganizacional democráticas, em que a colaboração entre pessoas estrutura uma colaboração entre organizações. A 
partir do nascimento de uma rede de cooperação produtiva, ações conjuntas, fluxos de pessoas, trocas de informações e instituições de apoio tornam-se fundamentais para o seu desenvolvimento, refletindo vantagem do acúmulo de capital social e humano nas organizações. Portanto, o capital social - indivíduos e suas relações de sociabilidade - podem auxiliar o nascimento e desenvolvimento de relacionamentos de inter-cooperação, por meio da estruturação de redes sociais, que, em conjunto, formam o capital social de pessoas e grupos/ organizações.

Outra vantagem do capital social de uma organização se traduz na criação de instituições de apoio à rede inter-firmas, por meio do estabelecimento de objetivos comuns entre as empresas e da confiança mútua. Pode também auxiliar no estabelecimento de parcerias com outras instituições externas, a partir da coesão e da força do grupo, proporcionadas por esse capital. Tal coesão permite, conseqüentemente, uma maior facilidade nas trocas entre organizações, facilitando a difusão do conhecimento entre estas, a partir da geração deste, proporcionada por atividades voltadas ao desenvolvimento do capital intelectual dos recursos humanos das instituições.

O capital social, em forma de redes de relacionamento interpessoais e instituições, estabelece, junto a outras formas de capital, como o humano (habilidades, competências e conhecimento) e o intelectual (conhecimento), condições para a criação de espírito empreendedor, necessidade fundamental para a competitividade de redes e clusters, estimulando a inovação e a aprendizagem coletiva. O papel do capital social pode ser sinteticamente esquematizado, conforme a figura a seguir. 
Figura 1 - O papel do capital social em relações de cooperação produtiva

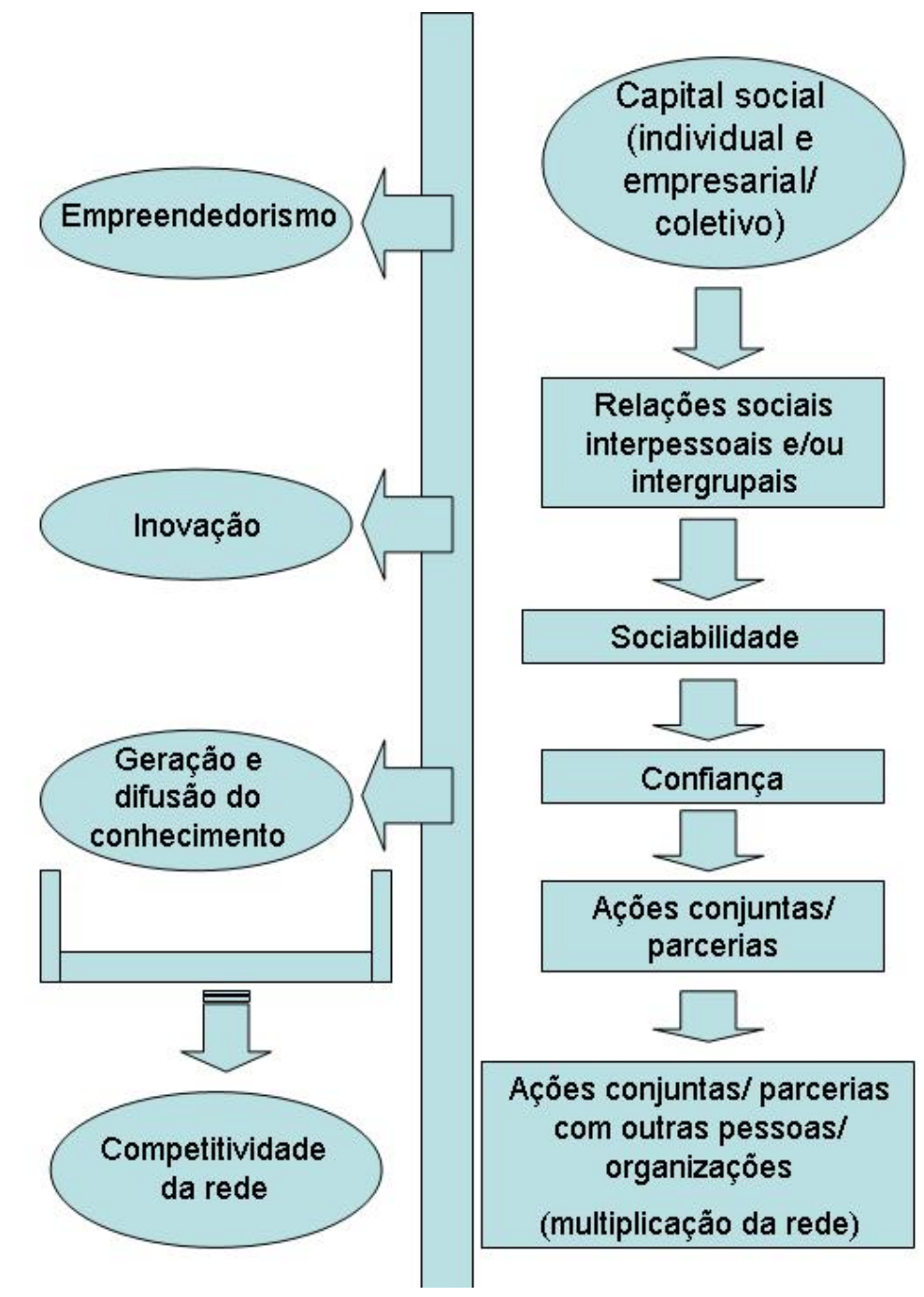

Fonte: Autoria própria (2009).

Portanto, o capital social influencia no estabelecimento e desenvolvimento de redes de cooperação interorganizacionais por meio do estabelecimento de redes/ relações sociais, através das quais os indivíduos e grupos desenvolvem confiança mútua, que permite parcerias e ações conjuntas. Em uma rede de cooperação ou cluster, os recursos humanos das empresas (notadamente seus proprietários e diretores) estabelecem redes sociais e confiança em outros indivíduos, podendo resultar na criação de uma rede de cooperação produtiva. Contribui ainda na constituição de capacidades empresariais como o empreendedorismo, a capacidade de inovação e a melhoria na geração e difusão do conhecimento, que permitem a melhoria da competitividade das empresas.

\begin{abstract}
In the last years, is notable the growth, on the part of micro, small and medium companies (MSMEs), the search for productive cooperation in form of nets, be these located spatially, as regional clusters, be virtual organizations and nets dispersed spatially, as a way for them to increase
\end{abstract}


its competitiveness. In this sense, it is important to point out the social capital concept as a tool that promote cooperation between companies, organizations and as a way for the development of abilities and collective efficiency among the agents belong to a specific cluster. Thus, the aim of this article is to analyze the social capital influence in the relationships development of productive cooperation networking and clusters of companies, contributing to a theoretical-methodological referential composition for researches about the theme. Basing on a bibliographical revision, the present work is characterized as an exploratory and multidisciplinary research and try to highlight the main theoretical contributions presented by several areas of knowledge, as administration, economy, production engineering and sociology. Some guidelines are also presented for social capital evaluation and of its interfaces with other capital forms in nets and gatherings of companies. Finally, the work reveals the benefits provided to companies by social capital accumulation, benefiting its competitiveness.

Key-words: social capital, productive cooperation networks, regional clusters.

\section{Referências}

ALBAGLI, S.; MACIEL, M. L. 2002. Capital Social e empreendedorismo local. Rio de Janeiro: UFRJ, 2002. Disponível em: <http://www.ie.ufrj.br/redesist/NTF2/NT\%20SaritaMLucia.PDF>. Acesso em 1 fev. 2007.

AMATO NETO, J. Redes de cooperação produtiva e clusters regionais: oportunidades para as pequenas e médias empresas. São Paulo: Atlas, 2000.

2005.

(Org.). Redes entre organizações: domínio do conhecimento e da eficácia operacional. São Paulo: Atlas,

BECATTINI, G. Sectors and/ or Districts: Some Remarks on the Conceptual Foundations of Industrial Economics. In: GOODMAN, E.; BAMFORD, J. (Eds.). Small Firms and Industrial Districs in Italy. London: Routledge, 1989. p 123-135.

BNDES (Banco Nacional de Desenvolvimento Econômico e Social). Notícias. Disponível em: $<$ http://www.bndes.gov.br/noticias/not620.asp $>$. Acesso em 15 nov. 2003.

BORTOLOTTI, F. Desenvolvimento de um sistema de indicadores para classificação e avaliação de arranjos produtivos locais. 2005. Trabalho de Formatura (Graduação em Engenharia de Produção) - Escola Politécnica, Universidade de São Paulo, São Paulo.

BOURDIEU, P. O capital social - notas provisórias. In: NOGUEIRA, M. A.; CATANI, A. (Orgs.). Pierre Bourdieu: escritos de educação. Petrópolis: Vozes, 1998. p. 65-69.

Questões de sociologia. Rio de Janeiro: Marco Zero, 1983.

. A economia das trocas simbólicas. São Paulo: Perspectiva, 1974.

BRITO, J. Cooperação interindustrial e redes de empresas. In: KUPFER, D.; HASENCLEVER, L. Economia Industrial: fundamentos teóricos e práticas no Brasil. 2 ed. Rio de Janeiro: Campus, 2002.

CASAROTTO FILHO, N. 2006. Garantia mutualista, pequenas empresas e desenvolvimento regional: situação atual e perspectivas no Brasil. Florianópolis: Agência Fórum Catarinense de Desenvolvimento. Disponível em: $<\underline{\mathrm{http}}$ ://www.forumcat.org.br/conteudo/? item $=65 \& \mathrm{fa}=43 \&$ PHPSESSID $=\mathrm{e} 38 \mathrm{e} 812336 \mathrm{~b} 59 \mathrm{ec} 127 \mathrm{f} 1 \mathrm{c} 618 \mathrm{e} 5 \mathrm{fc} 8 \mathrm{~d} 9 \mathrm{f}>\mathrm{Acesso}$ em 2 fev. 2007.

CASAROTTO FILHO, N.; PIRES, L. H. Redes de pequenas e médias empresas e desenvolvimento local: estratégias para a conquista de competitividade global com base na experiência italiana. São Paulo: Atlas, 1999.

CASSiolato, J. E.; LASTRES, H. M. M. Glossário de Arranjos Produtivos e Sistemas Inovativos Locais. SEBRAE, Rio de Janeiro, 2003.

CASTELlS, M. A sociedade em rede. São Paulo: Paz e Terra, 2000. 
COLEMAN, J. S. Foundations of social theory. Cambridge: The Belknap Press of Harvard University Press, 1990.

DEGENNE, A. Resenha de: Nan Lin. 2001. Social capital: a theory of social structure and action. Cambridge University Press, Cambridge. Tempo Social, revista de sociologia da USP, São Paulo, v. 16, n. 2. p. 303-305, 2004.

ELIAS, N.; SCOTSON, J. L. Os estabelecidos e os outsiders: sociologia das relações de poder a partir de uma pequena comunidade. Rio de Janeiro: Jorge Zahar, 2000.

ELIAS, N. A sociedade dos indivíduos. Rio de Janeiro: Jorge Zahar, 1997a.

Envolvimento e distanciamento. Lisboa: Dom Quixote, $1997 \mathrm{~b}$.

Introdução à sociologia. Lisboa: Edições 70, 1999.

GARCIA, R. C.; AMATO NETO, J. 2006. Aglomerações de pequenas e médias empresas (PMEs) e os sistemas locais de produção: contribuições para um referencial teórico. In: SEMINÁRIO INTERNACIONAL DE INOVAÇÃO NA PEQUENA E MÉDIA EMPRESA, 1., 2006, São Paulo. Anais. São Paulo: EPUSP/ Fundação Vanzolini, 2006. p. 1-16.

GONÇALVES, C. M.; ABREU, A. F. A identificação de competências em relações informais: o papel de brokers em rede interorganizacional de biotecnologia. In: ENCONTRO NACIONAL DE ENGENHARIA DE PRODUÇÃO (ENEGEP), 24., 2004, Florianópolis. Anais. Florianópolis: UFSC/ ABEPRO, 2004. p. 3777-3784.

GRANDORI, A.; SODA, G. Inter-firm network: Antecedents, mechanisms and forms. Organization Studies. Berlin, v. 16, n. 2, p. 183-205, 1995.

cross'ref

GRANOVETTER, M. Economic action and social structure. American Journal of Sociology, v. 91, n. 3, p. 451-481, 1985.

cross ${ }^{\text {ref }}$

GTZ (Deutsche Gesellschaft für Technische Zusammenarbeit). Work the net: A management guide for formal networks. New Delhi: GTZ, 2006.

GUEDES, M.; FORMICA, P. A economia dos parques tecnológicos. Rio de Janeiro: Anprotec, 1997.

GUIMARÃES, E. A. Crescimento e acumulação da firma (um estudo de organização industrial). Rio de Janeiro: Zahar, 1982.

HAGUENAUER, L.; GUIMARÃES, E. A. Complexos industriais: uma nota sobre conceitos e métodos de identificação empírica. Rio de Janeiro: IEI/UFRJ, 1983.

HOFFMAN, J.; KAPLINSKY, R. Driving force: the global restructuring of technology, labor and investment in the automobile industry. Colorado: West View Press, 1988.

HUMPHREY, J.; SCHMITZ, H. Trust and inter-firm relations in developing and transition economies. Sussex: IDS, University of Sussex, 1998.

KANTER, R. M. When giants learn cooperative strategies. Planning Review, Chicago, v. 18, n.1, p. 15-22, 1990.

LOPES, T. C.; CABELLEIRA, D. M. Governança e confiança, aspectos fundamentais na criação de capital social: o caso da prefeitura de Taquara e da indústria moveleira do Vale do Paranhana - RS/Brasil. In: ENCONTRO NACIONAL DE ENGENHARIA DE PRODUÇÃO (ENEGEP), 24., 2004, Florianópolis. Anais. Florianópolis: UFSC/ ABEPRO, 2004. p. 3793-3800.

MARSHALL, A. Principles of Economics. New York: The Macmillan Company, 1952.

MARTELETO, R. M.; SILVA, A. B. O. Redes e capital social: o enfoque da informação para o desenvolvimento local. Ciência da Informação, Brasília, v. 33, n.3, p. 41-49, 2004.

MAXIMIANO, A. C. A. Introdução à administração. 6 ed. São Paulo: Atlas, 2006. 
MEYER-STAMER, J. 2001. Estratégias de desenvolvimento local e regional: clusters, política de localização e competitividade sistêmica. Policy Paper, São Paulo, p. 1-27, 2001.

NEIBURG, F. A sociologia das relações de poder de Norbert Elias. In: ELIAS, N.; SCOTSON, J. L. Os estabelecidos e os outsiders: sociologia das relações de poder a partir de uma pequena comunidade. Rio de Janeiro: Jorge Zahar, 2000. p. 7-11.

NOGUEIRA, M. A.; CATANI, A. M. (Orgs.). Pierre Bourdieu: escritos de educação. Petrópolis: Vozes, 1998.

ORTIZ, R. (Org.). Pierre Bourdieu: sociologia. São Paulo: Ática, 1983.

PAIVA JÚNIOR, F. G.; FERNANDES, N. C. M.; ALMEIDA, L. F. L. O capital social da empresa de base tecnológica expandida pela relacionalidade do empreendedor. In: ENCONTRO NACIONAL DE ENGENHARIA DE PRODUÇÃO (ENEGEP), 26., 2006, Fortaleza. Anais. Fortaleza: ABEPRO, 2006. p. 1-8.

PASSOS, F. H.; DIAS, C. C.; CRUZ, R. C. Capital social, competências e demandas tecnológicas de arranjos produtivos locais: o caso do APL de sisal em Valente, Bahia. Economia e Gestão, Belo Horizonte, v. 5, n. 10, p. 92112, 2005.

PIZARRO, N. Un nuevo enfoque sobre la equivalencia estructural: lugares y redes de lugares como herramientas para la teoría sociológica. REDES - Revista hispana para el análisis de redes sociales, Madrid, v. 5, n. 2, p. 1-14, 2003.

PORTER, M. 1998a. Clusters and the new economics of competition. Harvard Business Review, Harvard, v.76, n.6, 1998a.

On Competition. Harvard: Harvard Business Review Book, 1998 b.

POSSAS, M. L. Complexos industriais: uma proposta de metodologia. Campinas: Instituto de Economia UNICAMP, 1984.

PUTNAM, R. Fazendo a democracia funcionar. Rio de Janeiro: Ed. FGV, 1996.

PYKE, F. Industrial Development through small firm cooperation: theory and practice. Geneve: International Labour Office, 1992.

PYKE, F.; SENGENBERGER, W. (Eds.). Industrial districts and local economic regeneration. Geneve: International Institute for Labour Studies, 1992.

REIS, B. P. W. Capital social e confiança: questões de teoria e método. Revista de Sociologia e Política, Curitiba, n. 21, p. 35-49, 2003.

RIBAUT, M.; MARTINET, B; LEBIDOIS, D. A gestão das tecnologias. Lisboa: Dom Quixote, 1995.

SANABIO, M. T. Redes organizacionais: paradigmas e capital social. In: ENCONTRO NACIONAL DE ENGENHARIA DE PRODUÇÃO (ENEGEP), 26., 2006, Fortaleza. Anais. Fortaleza: ABEPRO, 2006. p. 1-9.

SANTOS, S. A.; PEREIRA, H. J.; ABRAHÃO FRANÇA, S. E. Cooperação entre as micro e pequenas empresas. São Paulo: SEBRAE, 1994.

SCHMITZ, H. Collective efficiency and increasing returns. IDS Working Paper, Brighton, n. 50, 1997.

. On the Clustering of Small Firm. IDS Bulletin, Brighton, v.23, n. 3, 1992.

. Industrial Districts: Model and reality in Baden-Württenberg,Germany. In: PYKE, F.; SENGENBERGER, W. (Eds.). Industrial districts and local economic regeneration. Geneve: International Institute for Labour Studies, 1991.

Small Firms and Flexible Specialization. Sussex: IDS, University of Sussex, 1989.

SEBRAE (Serviço Brasileiro de Apoio às Micro e Pequenas Empresas). Metotologia de Desenvolvimento de Arranjos Produtivos Locais. Projeto Promos/ Sebrae/ BID. Versão 2.0. SEBRAE, Brasília, 2004.

SILVA, M. F. G. Cooperation, social capital and economic performance. Brazilian Journal of Political Economy, v. 26, n. 3 (103), p. 345-363, 2006. 
SUZIGAN, W. Aglomerações industriais como focos de políticas. Revista de Economia Política, v. 21, n. 3, p. 27-39, 2001.

WEGNER, D.; SCHMITT, C. L.; FOSSÁ, M. I. A importância da cultura para o sucesso na formação e desenvolvimento de redes empresariais. In: ENCONTRO NACIONAL DE ENGENHARIA DE PRODUÇÃO (ENEGEP), 24., 2004, Floianópolis. Anais. Florianópolis: UFSC/ ABEPRO, 2004. p. 3697-3704.

WEGNER, D.; WITTMANN, M. L. 2004.'O papel do agente externo (broker) naformação de redes interorganizacionais. In: ENCONTRO NACIONAL DE ENGENHARIA DE PRODUÇÃO (ENEGEP), 24., 2004, Floianópolis. Anais. Florianópolis: UFSC/ ABEPRO, 2004. p. 3624-3631.

WILLIAMSON, O. E. The economic institutions of capitalism - firms, markets, relational contracting. New York: The Free Press, 1985.

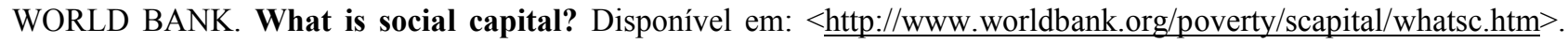
Acesso em 21 nov. 2003.

\section{Inserir aqui dados completos de TODOS os autores:}

Nome completo: João Amato Neto

Filiação institucional: Universidade de São Paulo

Departamento: Departamento de Engenharia de Produção

Função ou cargo ocupado: Professor titular

Endereço completo para correspondência (bairro, cidade, estado, país e CEP): Avenida Prof. Almeida Prado, 531 - travessa 2 - 05508-900 - Cidade Universitária - São Paulo-SP, Brasil

Telefones para contato: (11) 3091-5363 - ramal 409

e-mail: amato@usp.br

Nome completo: Rita de Cássia Fucci Amato

Filiação institucional: Universidade Federal de São Carlos

Departamento: Departamento de Educação

Função ou cargo ocupado: Pós-graduada (Doutora)

Endereço completo para correspondência (bairro, cidade, estado, país e CEP): Avenida Ibijaú, 45 apto. 123 - 04524-020 - Moema - São Paulo-SP, Brasil.

Telefones para contato: (11) 5052-6159

e-mail: fucciamato@terra.com.br 